\title{
Expressões nominais referenciais em narrativas infantis: funções cognitivo- discursivas envolvidas na construção de objetos-de-discurso
}

\author{
Referential nominal expressions in children's \\ narratives: cognitive-discursive functions involved \\ in the construction of objects-of-discourse
}

\author{
Marcela Regina Vasconcelos da Silva \\ Universidade Federal da Paraíba \\ Faculdade Frassinetti do Recife
}

\begin{abstract}
This paper analyzes the cognitive-discursive functions of referential nominal expressions used in narrative texts produced by elementary schoolchildren. For this purpose, we adopt the theoretical position that language is something that is constituted dialogically in a process of interaction, such that the text is the place of interaction and the constitution of subjects. Consequently, language cannot be understood as transparent, as it does not reflect the real. The objects constructed in the discursive process reconstruct the data of the real based on the interpretation and perception of the subjects. Therefore, the activity of referencing achieves a construction and organization of reality, which justifies the importance of socially and cognitively analyzing the functions involved in this activity.
\end{abstract}

Keywords

Sociocognition, Reference, Text. 


\section{Resumo}

Neste artigo, analisamos as funções cognitivo-discursivas das expressões nominais referenciais utilizadas em textos narrativos produzidos por estudantes do Ensino Fundamental. Para tanto, adotamos a postura teórica de acordo com a qual a língua é algo que se constitui dialogicamente, no processo da interação, de modo que o texto se configura como o próprio lugar da interação e da constituição dos sujeitos. Consequentemente, a língua não pode ser entendida como transparente, visto que não reflete o real; os objetos construídos no processo de discursivização reelaboram, de acordo com a interpretação e a percepção dos sujeitos, os dados do real. Portanto, a atividade de referenciação realiza um processo de construção e ordenação da realidade, o que justifica a importância de analisar sociocognitivamente as funções envolvidas na realização dessa atividade.

\section{Palavras-chave}

Sociocognição, Referenciação, Texto. 


\section{Introdução}

atividade de referir é extremamente relevante para a construção de sentidos, visto que, entre outras funções, constrói objetos-de-discurso. 1 É necessário se ter em mente que essa construção não estabelece uma relação direta entre uma forma linguística e um referente extralinguístico.

Neste trabalho, adotamos a perspectiva teórica defendida por Apothéloz \& Reicheler-Béguelin (1995), Koch (2004), Koch \& Marcuschi (1998), Mondada (2005) e Mondada \& Dubois (1995), segundo a qual, à medida que os sujeitos produzem textos, são construídos objetos-do-discurso resultantes de um processo contínuo de interação entre percepção, linguagem e ação social.

Desse modo, nem sempre aquilo que se denomina “a realidade” está isento das nossas práticas culturais, que, não raras vezes, determinam a forma como percebemos o mundo ao nosso redor e expressamos essas percepções por meio da linguagem. Conforme explicam Apothéloz \& Reicheler-Béguelin (1995, p. 228), “'objetos-do-discurso' não preexistem “naturalmente” à atividade cognitiva e interativa dos sujeitos falantes, mas devem ser concebidos como produtos - fundamentalmente culturais - desta atividade".

Por essa razão, de acordo com essa perspectiva, podemos afirmar que a língua não transmite nem reflete o real, ela constrói o próprio real num processo de interação contínua entre percepção, linguagem e ação social, pois, conforme explica Koch (2004),

não se entende aqui a referência no sentido que lhe é mais tradicionalmente atribuído, como simples representação extensional de referentes do mundo extramental, mas sim como aquilo que designamos, representamos, sugerimos quando usamos um termo ou criamos uma situação discursiva referencial com essa finalidade: as entidades designadas são vistas como objetos-de-discurso e não como objetos-do-mundo. 
Diante disso, é possível afirmar que nossas práticas culturais determinam a forma como percebemos o mundo ao nosso redor e expressamos essas percepções por meio da linguagem. Segundo Koch (2004, p. 57),

nosso cérebro não opera como um sistema fotográfico do mundo, nem como um sistema de espelhamento, ou seja, nossa maneira de ver e dizer o real não coincide com o real. Ele reelabora os dados sensoriais para fins de apreensão e compreensão. E essa reelaboração se dá essencialmente no discurso.

Logo, quando ativamos nossas percepções, estamos nos engajando em um processo de construção e ordenação da realidade, constituindo-se os referentes nessa dimensão perceptivo-cognitiva. Dessa forma, objetos-do-discurso são construídos pelos sujeitos sociais, no curso da interação, de acordo com as finalidades práticas dos enunciadores, que constroem essas formas simbólicas em função dos sentidos pretendidos.

Há, portanto, uma (re)construção da realidade, tendo em vista a materialização de uma proposta de sentido. Consequentemente, a análise das funções que as expressões nominais referenciais podem exercer é uma forma de estudar importantes estratégias de construção de sentidos.

Por isso, esta pesquisa se propõe a analisar a função de expressões nominais referenciais que aparecem em textos produzidos por alunos concluintes da 4 a série do Ensino Fundamental de uma escola em Jaboatão dos Guararapes, em Pernambuco. O conhecimento construído com base em tal estudo oferecerá alguns elementos para que se conheçam os recursos utilizados por crianças em fase de conclusão do Ensino Fundamental I para realizar o seu projeto de dizer.

\section{0 que é coesão?}

Toda comunicação verbal ocorre por meio de textos, que não podem ser considerados sequências de palavras, afinal, o todo complexo do texto vai além da sua realização linguística, já que os sentidos não assentam sobre as palavras, eles são cognitivamente construídos numa complexa interação de conhecimentos de ordem interativa, linguística, social, histórica, etc. Apesar de um texto não se resumir à superfície textual, é inegável a importância desta para que se reconheça uma determinada sequência linguística como texto. 
Dessa forma, pode-se perceber que, embora a justaposição de elementos linguísticos não seja suficiente para que haja um texto, o aparato linguístico não se organiza de modo aleatório, o que significa afirmar que obedece a princípios constitutivos e reguladores da própria textualidade.

Um desses importantes princípios é a coesão, fenômeno que contribui para a organização dos segmentos linguísticos na superfície textual, ligando-os, interconectando-os, a fim de constituir uma unidade reconhecida como relevante e adequada.

Sendo assim, a coesão diz respeito às ligações que se podem estabelecer entre palavras, orações, parágrafos e blocos supraparagráficos, de modo que se construa uma continuidade que ultrapassa a sequência linear perceptível na superfície sonora ou visual. Na verdade, cada parte do texto está ligada a uma ou diversas outras partes antecedentes ou subsequentes, das quais depende para que possa ser compreendida, uma vez que o texto não é formado por palavras soltas.

Por esse motivo, Antunes (2005, p. 48) afirma que "a função da coesão é exatamente a de promover a continuidade do texto, a sequência interligada de suas partes, para que não se perca o fio de unidade que garante a sua interpretabilidade".

Essa sequência interligada de partes do texto não ocorre apenas na superfície, visto que a organização superficial do texto se realiza intrinsecamente relacionada aos conceitos e relações de sentido pretendidos na atividade comunicativa. Logo, a continuidade linguística manifestada na superfície sinaliza a continuidade de sentidos que está de acordo com as intenções pretendidas, ou seja, materializam-se, por meio dos recursos coesivos que garantem as ligações entre segmentos do texto, as ligações conceituais estabelecidas no plano dos sentidos.

Segundo Antunes (2005, p. 49),

quando pretendemos que nossos textos sejam coesos, pretendemos que seja preservada sua continuidade, a sequência interligada de suas partes, para que se efetive a unidade do sentido e das intenções de nossa interação verbal. Para que, afinal, possamos nos fazer entender com sucesso. 
Assim, embora seja um fenômeno que se verifica na superfície textual, a coesão envolve princípios semânticos e cognitivos, uma vez que os recursos formais que estabelecem ligação entre elementos linguísticos do texto permitem a ativação de relações de sentido. Diante disso, compreende-se por que, para Koch (2002a, p. 18), “o uso de elementos coesivos dá ao texto maior legibilidade, explicitando os tipos de relações estabelecidas entre os elementos linguísticos que o compõem”.

Essa dimensão já era reconhecida por Halliday; Hasan (1976), para quem o conceito de coesão, considerada como parte do sistema da língua, uma vez que se realiza através do sistema léxico-gramatical, deveria ser analisado como um conceito semântico, já que esse fenômeno ocorre quando, no texto, um elemento, para ser compreendido, depende de outro.

Eles identificavam cinco mecanismos de coesão: referência, substituição, elipse, conjunção e coesão lexical. Todavia, os próprios autores reconheciam que essas categorias não eram as únicas por meio das quais uma determinada sequência linguística poderia se tornar coesa. Assim, Halliday e Hasan já indicavam a existência de outros mecanismos capazes de estabelecer ligações textuais.

Além dessa lacuna deixada pela proposta desses teóricos, percebeu-se que era "bastante questionável” (KOCH, 2004, p. 35) a distinção feita entre referência e substituição, bem como a definição de elipse como substituição por zero. Por esse motivo, alguns estudiosos da linguagem optaram por analisar os recursos coesivos dividindo-os de acordo com sua relação com os dois grandes movimentos de construção textual: a referenciação e a sequenciação. Tendo em vista os objetivos deste trabalho, vamos nos deter na referenciação.

\section{A referenciação}

Segundo Mondada (2005, p.11),

a questão da referência atravessa a filosofia da linguagem e a Linguística, assumindo formas teóricas diferenciadas: para uns, a referência é concebida no interior de um modelo de correspondência entre as palavras do discurso e os objetos do mundo, de modo que a validade das primeiras é avaliada em um quadro vericondicional, para outros, a referência é resultado de um processo dinâmico e, sobretudo, intersubjetivo, que se estabelece no quadro das 
interações entre locutores, e é suscetível de se transformar no curso dos desenvolvimentos discursivos, de acordos e desacordos.

Nesta pesquisa, assumimos a perspectiva teórica adotada por Apothéloz \& Reicheler-Béguelin (1995), Koch (2004), Koch \& Marcuschi (1998), Mondada (2005) e Mondada \& Dubois (1995), de acordo com a qual o discurso não é reflexo de objetos do mundo real; defendemos que as estruturações linguísticas reelaboram os dados da realidade no interior do discurso.

Sendo assim, aquilo que se considera o real, na verdade constitui-se como um produto predefinido por nossas práticas e concepções culturais, que condicionam nossa percepção, a qual é reforçada pela linguagem, conforme defende Koch (2004, p. 51), ao afirmar que:

percebemos os objetos tal como previamente definidos por nossas práticas culturais: a "realidade” é fabricada por toda uma rede de estereótipos culturais, que condicionam a própria percepção e que, por sua vez, são garantidos e reforçados pela linguagem, de modo que o processo de conhecimento é regulado por uma interação contínua entre práxis, percepção e linguagem.

Diante disso, compreende-se por que é correto afirmar que nossas práticas culturais determinam, em boa medida, a forma como percebemos o mundo ao nosso redor e expressamos essas percepções por meio da linguagem. Por sua vez, a linguagem também condicionará nossas percepções, do que resulta a constatação de que o conhecimento é construído na constante interação entre práticas socioculturais, percepção e linguagem.

Logo, conclui-se que não seria coerente assumir uma visão referencial da língua e da linguagem, uma vez que não há relação especular entre as palavras e os objetos do mundo. Compreendemos a referenciação como uma atividade discursiva que implica considerar o referente como um evento cognitivo construído, grande parte das vezes, por nossas percepções culturais, considerando a referência "como uma ação praticada pelo sujeito produtor da interação" (ANTUNES, 1996, p. 67).

Com essa postura, de acordo com Koch (2002b, p. 79), 
a referência passa a ser considerada como o resultado da operação que realizamos quando, para designar, representar ou sugerir algo, usamos um termo ou criamos uma situação discursiva referencial com essa finalidade: as entidades designadas são vistas como objetos-de-discurso e não como objetos-do-mundo.

Isso significa que a atividade de referenciação não consiste na nomeação da realidade, mas na construção do real, à medida que, sociocognitivamente, interagimos com o mundo ao redor e o criamos, a partir de nossas percepções, no interior de uma situação discursiva.

Portanto, segundo a perspectiva teórica adotada nesta pesquisa, quando construímos objetos-do-discurso, não estamos estamos apenas nomeando objetos do mundo que foram apreendidos por nosso cérebro, como se pudéssmos reproduzir de modo idêntico, por meio da linguagem, uma imagem congelada captada pelo cérebro. Operamos uma reelaboração dos dados que são enviados a nosso cérebro e construímos os objetos-do-discurso. Dessa maneira, fica evidente que a atividade de referenciação não pode ser compreendida como o estabelecimento de uma ligação entre um segmento linguístico e um antecedente, tampouco com algum objeto do mundo. É um processo dinâmico e complexo de reelaboração de dados, com bases em práticas socioculturais, levando em consideração conhecimentos de ordem interacional, linguística, cognitiva, etc., a fim de promover uma reconstrução da realidade, a qual é criada no seio da discursivização.

Em decorrência disso, aceitamos a concepção teórica defendida por Koch (2004, p. 61), segundo a qual "os processos de referenciação são escolhas do sujeito em função de um querer-dizer. Os objetos-de-discurso não se confundem com a realidade extralinguística, mas (re)constroem-na no próprio processo de interação”.

\section{As expressões nominais referenciais}

O uso de expressões nominais definidas é uma das mais produtivas formas de se estabelecer a referenciação. Essas expressões se caracterizam como formas linguísticas constituídas por, no mínimo, um determinante definido, que acompanha um nome, núcleo da expressão.

Essas formas são resultantes das escolhas, emmeio às diversas possibilidades de caracterização de um referente, da propriedade mais relevante em uma dada 
situação de interação. Por esse motivo, elas revelam o que o produtor textual deseja enfatizar em um dado referente, já que a escolha de uma característica a ser ressaltada por meio da expressão referencial ocorre de acordo com as intenções do locutor.

Segundo Koch (2004, p. 68-69), “o uso de uma descrição definida implica sempre uma escolha dentre as propriedades ou qualidades capazes de caracterizar o referente, escolha esta que será feita, em cada contexto, em função do projeto de dizer do produtor do texto".

Em virtude da importância dessas expressões, julgamos interessante fazer essa análise, uma vez que é importante usar de modo produtivo as expressões nominais referenciais, o que contribui para o domínio das competências necessárias à escrita de textos por meio dos quais os alunos podem atuar mais efetivamente em contextos sociais que exigem o uso da escrita.

Assim, para a realização deste trabalho, analisamos textos produzidos por alunos concluintes da $4^{\mathrm{a}}$ série do Ensino Fundamental de uma escola da rede particular do município de Jaboatão dos Guararapes, em Pernambuco. No final do ano, os alunos leram o livro Fábulas de Esopo e analisaram as características do gênero fábula. Em seguida, fizeram um levantamento de ditos populares, cujos sentidos foram analisados em sala de aula. Posteriormente, participaram de uma atividade de produção de fábulas cuja moral deveria ser um dito popular escolhido pelo aluno. Foi feita uma primeira leitura pela professora e os textos (sem identificação dos autores) foram colocados em transparências, para que fossem discutidos na aula de Produção Textual. Após essa discussão, os textos foram devolvidos aos alunos, que os reescreveram. Nessa segunda versão, analisamos o papel das expressões nominais referenciais, a fim de investigar estratégias por meio das quais esses textos realizam o seu projeto de dizer.

Percebemos que, nos textos analisados, as expressões nominais referenciais desempenham as funções cognitivo-discursivas a seguir.

\section{Ativação/ reativação na memória}

Em muitos textos, encontram-se referentes que são ativados (ou reativados) na memória do interlocutor por meio de expressões nominais referenciais que fazem remissão a algum elemento presente (ou sugerido) no cotexto precedente. 
Com isso, elas promovem uma refocalização do referente, pois, ao mesmo tempo em que recategorizam informações já conhecidas, apresentam informações novas. Por esse motivo, são consideradas formas híbridas: têm função referenciadora e predicativa, uma vez que veiculam informações dadas e novas.

Eles começaram a briga na fila e continuaram na sala. A professora ouviu os gritos do corredor e voltou correndo.

O menino pegou os carrinhos e o boneco do Homem Arainha e foi pro quintau. Derrepente um barulho fez ele parar a brincadeira.

É possível observar que as expressões destacadas são formas híbridas: encontram-se ancoradas em um segmento anterior e, concomitantemente, permitem a continuidade do texto.

No primeiro exemplo, a expressão os gritos está ancorada nas informações anteriores ("eles começaram a briga na fila e continuaram na sala”). Embora seja uma informação nova, a introdução desse novo objeto-do-discurso (os gritos) não causa surpresa no leitor, já que está ancorada na informação anterior ( a briga), que ativou um frame do qual gritos podem fazer parte.

No segundo trecho, observamos que a expressão a brincadeira introduz um novo referente, o qual está ancorado no co-texto precedente ("o menino pegou os carrinhos e o boneco do Homem Arainha e foi pro quintau”). Como foram mencionados brinquedos no co-texto precedente, é possível inferir que eles seriam utilizados para realizar uma brincadeira. Quando este objeto-do-discurso (a brincadeira) surge, pela primeira vez no texto, ele não se apresenta como uma informação essencialmente nova, uma vez que já havia sido ativada na memória do leitor.

Logo, percebemos que essas são formas referenciadoras e predicativas.

\section{Encapsulamento (sumarização) e rotulação}

Algumas expressões nominais referenciais operam um encapsulamento de informações presentes em segmentos anteriores, transformando em expressões nominais as predicações feitas no co-texto precedente. Assim, elas sintetizam informações que as precedem, as quais se constituem como informaçõessuporte. Desse modo, uma parte do co-texto é transformada em um novo objeto- 
de-discurso, que, geralmente, apresenta um termo genérico como nome-núcleo, o qual depende do co-texto para ser compreendido.

O homem saiu de casa cedo mais chegou atrajado no trabalho. Ele perdeu o ónibus que sempre pegava porque teve que parar para catar as moedas que cairam da mão dele.

Ele ficou com tanta raiva que contou esse fato no trabalho.

Era uma vez um homem muito rico, que vio seu filho ficar muito doente piorar muito ir para os médicos e hospitais mais caros e acabar morrendo no final.

Essa desgraça deixou o homem muito infeliz um dia ele pela frente de uma casa muito pobre e vio um homem muito pobre com seus filhos reunidos para o jantar.

O homem rico vio essa cena e ficou com inveja do homem pobre.

Mas o tempo foi passando e nada dá aguiasinha voar aí a mãe dele começou a ficar com raiva.

Todas as amigas riam dessa situação, ficavam debochando: Esse filhote nasceu sem asas?

O coelho ingenuo começou a trabalhar feito um louco todo dia ele colhia vinte cenouras mas ele não aguentou essa situação nem até o final da semana: caiu de cama com estafa e passou dias sem colher nenhuma cenoura.

Nesses exemplos, constatamos que esse fato, essa desgraça, essa cena, dessa situação e essa situação encapsulam o co-texto precedente, criando expressões nominais referenciais com nomes-núcleo inespecíficos, cuja compreensão depende dessa associação com o co-texto.

As expressões em destaque se constituem como objetos discursivamente construídos, os quais não podem ser interpretados tendo em vista supostas estruturas “objetivas” da realidade, uma vez que se configuram como estruturações impostas à realidade por meio da percepção.

Com isso, percebe-se que a percepção cria esses referentes; afinal, a forma como esses fenômenos são apreendidos pela interpretação humana éfundamental para o desenvolvimento de conceitos abstratos dentro da cena enunciativa. 


\section{Organização macroestrutural}

Outra importante função exercida pelas expressões nominais referenciais diz respeito ao encerramento de uma etapa textual, por meio do encapsulamento de um segmento anterior, a fim de que se possa passar a um novo estágio.

\section{O albúm de figurinhas}

Era uma vez um menino chamado Matheus. Um dia ele saiu com o pai e ganhou um albúm para colar figuras. Todo dia Matheus ganhava um real do pai para comprar um pacote de figurinhas.

Essa diversão durou uma semana. O menino estava bem feliz, mas aí ele viu que Pedro ganhava dois reais todos os dias para comprar figurinhas. Aí Matheus também queria ganhar o que seu amigo ganhava e começou a chorar toda vez que ganhava um real porque queria ganhar dois.

Essa situação deixou os pais de Matheus com raiva e eles acharam que ele tava passando dos limites. Aí eles pararam de dar dinheiro para Matheus comprar figurinhas.

Essa decisão deixou Matheus triste pois ele não conseguio completar se albúm .

Moral: melhor um passarinho na mão do quê dois voando.

Logo, as formas nominais essa diversão, essa situação e essa decisão realizam o encapsulamento de uma parte do texto, sinalizando o fechamento dessa parte, que é mantida na informação nova. Sendo assim, ocorre uma mudança no tópico discursivo, mas a continuidade tópica é mantida, ocorrendo simultaneamente um movimento de retroação e um de progressão textual. Evidencia-se, então, a importância dessas expressões nominais na marcação de parágrafos, uma vez que contribuem na estruturação do texto.

Mais uma vez, constata-se que não houve uma representação extensional de objetos do mundo extramental: foram criados objetos-do-discurso, os dados sensoriais foram reelaborados no interior da situação discursiva, de modo que sua interpretação não depende da localização de um termo precedente ou do estabelecimento de uma relação com algum objeto específico no mundo.

Logo, percebe-se que os processos de referenciação realizados pelos autores foram possíveis mediante as escolhas feitas por esses sujeitos tendo em vista um querer-dizer. Não há equivalência entre os objetos-do-discurso 
construídos e a realidade extralinguística, que foi reconstruída no curso da interação.

\section{IV.Atualização de conhecimentos por meio de retomadas realizadas pelo uso de um hiperônimo}

Na tessitura textual, um termo pode ser retomado por seu hiperônimo, que, mesmo desconhecido do interlocutor (ou não atualizado em sua memória discursiva), pode ser inferido com base nas pistas textuais.

Era uma vez uma comunidade onde todos os pássaros viviam felizes. Eles ajudavam uns aos outros e todos se davam bem. Só que lá vivia também um urubu muito rico que não nada por nimguém. A ave de rapina só pensava nela mesma ai um dia o pássaro malvado ficou preso numa armadilha e pediu ajuda aos outros pássaros.

Era um vez um macaco que fez amizade com dois peixes, uma tartaruga um jacaré e dois carnagueijos. Quando a mare baixava o macaco ia conversar com esses animais marinhos.

Com o uso dos hiperônimos a ave de rapina e esses animais marinhos, os conhecimentos do interlocutor podem ser ampliados ou atualizados.

\section{Introdução de informações novas}

É possível caracterizar melhor o referente utilizando expressões nominais (definidas ou indefinidas), que introduzem novas informações no texto.

Essa diversão durou uma semana. O menino estava bem feliz, mas aí ele viu que Pedro ganhava dois reais todos os dias para comprar figurinhas. Aí Matheus também queria ganhar o que seu amigo ganhava e começou a chorar toda vez que ganhava um real porque queria ganhar dois.

Nesse exemplo, constata-se que seu amigo, à proporção que faz referência à informação de que Pedro ganhava dois reais, introduz uma informação nova: Pedro é amigo de Matheus. Com isso, acrescentam-se novas informações acerca do referente. 
Esse exemplo mostra como um “objeto" textual (Pedro) pode ser introduzido e colocado em foco na memória discursiva para, em seguida, uma forma referencial (seu amigo) operar uma reintrodução do objeto já existente, modificando-o pelo acréscimo de novas categorizações, informações ou avaliações sobre o referente. A construção do objeto-do-discurso seu amigo está ancorada na informação precedente, uma vez que o "novo" objeto-do-discurso é introduzido sob a forma do dado.

\section{Orientação argumentativa}

Muitas expressões nominais indicam uma direção argumentativa. Essas expressões podem ser metafóricas ou não.

\section{O urubu egoísta}

Era uma vez uma comunidade onde todos os pássaros viviam felizes. Eles ajudavam uns aos outros e todos se davam bem. Só que lá vivia também um urubu muito rico que não nada por nimguém. A ave de rapina só pensava nela mesma ai um dia o pássaro malvado ficou preso numa armadilha e pediu ajuda aos outros pássaros. As aves nem ligaram para os apelos do urubu e foram alegres cantando para casa. Moral: É dando que se recebe.

\section{O médico}

Era uma vez um médico que queria ganhar muito dinheiro. $\mathbf{O}$ homem ambicioso só queria ganhar cada vez mais e nunca tinha tempo para sua família.

Um dia o filho dele acordou meio mole pediu para o pai ver se ele precisava de algum remédio. Mas o médico ganicioso disse: - Que tinha uma consulta e não podia se atrasar.

Ele foi trabalhar e o filho ficou em casa doente.

Moral: em casa de ferreiro, o esperto é de pau. 


\section{O coelho bobo}

Era uma vez um coelho que conseguia colher dez cenouras por dia. Um dia ele contou isso para comadre coruja ela era muito viva e quis fazer uma brincadeira com o coelho. A amiga espertinha disse que o coelho devia deixar de ser preguiçoso e colher vinte cenouras todos os dias. O coelho ingenuo começou a trabalhar feito um louco todo o dia ele colhia vinte cenouras mas ele não aguentou essa situação nem até o final da semana: caiu de cama com estafa e passou dias sem colher nenhuma cenoura.

Moral: mais vale um passaro na mão do que dois voando.

Nos textos analisados, percebe-se que as expressões o homem ambicioso, o médico ganicioso (ganancioso), a amiga espertinha, o coelho ingênuo não exercem apenas a função de referir, mas operam uma avaliação do referente, expressando juízos de valor.

Conforme já foi discutido, a construção de objetos-do-discurso se dá através de escolhas realizadas pelo sujeito, em função do querer-dizer. As expressões linguísticas destacadas nos exemplos anteriores evidencia como a percepção contribui para a construção de objetos-do-discurso, os quais, nos exemplos citados, demonstram opiniões dos produtores dos textos e apresentam propriedades atribuídas aos referentes pela percepção dos autores.

\section{Categorização metaenunciativa de um ato de enunciação}

As expressões nominais definidas também podem ser usadas para que seja feita uma avaliação ou categorização da enunciação realizada. Isso pode ocorrer por meio da classificação da própria entidade linguística pela qual o conteúdo se realiza (com o uso de expressões que apresentam termos como frase, parágrafo, etc. como nomes-núcleo), bem como por meio da classificação da ação praticada pelo próprio autor ou por uma outra pessoa, o que envolverá uma reflexão sobre o dizer ( de que resultam expressões cujos nomesnúcleo podem ser declaração, protesto, apelo, etc.).

Todos ficaram tristis mais o homem disse que ele ia encontra o bilhete e eles ião morar numa manção bem bonita. Ninguem acreditou nessa promessa mais ai um dia o homem chegou com um carro emportado para levar eles para morar na manção pois tinha achado o bilhete. 
A ave de rapina só pensava nela mesma ai um dia o pássaro malvado ficou preso numa armadilha e pediu ajuda aos outros pássaros. As aves nem ligaram para os apelos do urubu e foram alegres cantando para casa.

Mas o tempo foi passando e nada dá aguiasinha voar aí a mãe dele começou a ficar com raiva.

Todas as amigas riam dessa situação, ficavam debochando: Esse filhote nasceu sem asas?

A mãe estava tão triste que nem respondia a essa pergunta.

Nos exemplos acima, os objetos-do-discurso nessa promessa, os apelos do urubu e essa pergunta foram construídos e categorizados conforme a percepção dos produtores dos textos em relação aos atos enunciativos realizados. Eles não correspondem a objetos-do-mundo, na verdade, operam uma avaliação sobre o dizer atribuído, respectivamente, ao homem que ganhou na loteria, ao urubu e às amigas da águia cujo filhote não conseguia voar.

\section{Considerações finais}

Neste trabalho, constatamos que são múltiplas as funções das expressões nominais referenciais, para cuja compreensão é necessária a interação de diversos níveis de conhecimentos, sejam esses de ordem linguística, interacional, histórica, social, cognitiva, etc.

Essa constatação ratifica a noção de acordo com a qual não se concebem mais aqueles estudos linguísticos que consideram a atividade de referir como algo responsável por estabelecer uma relação direta entre uma forma linguística e um referente extralinguístico, como se entre palavras e objetos-do-mundo houvesse uma relação especular.

Com isso, pode-se concluir que as palavras não refletem os entes do mundo, de tal forma que o referente não pode ser considerado como um reflexo de estruturas da realidade objetiva, mas o produto da maneira como percebemos e interpretamos o mundo.

Com base na análise empreendida, constatamos que, quando optam por usar uma expressão nominal referencial, os sujeitos operam escolhas significativas sobre os elementos linguísticos disponíveis, o que faz com que a textualização realizada não se constitua como uma simples denominação de um 
objeto-do-mundo, mas se configure como uma (re)construção da realidade em função de um querer-dizer.

Logo, constatamos que, mesmo em textos considerados “simples”, como as fábulas produzidas por estudantes da $4^{\mathrm{a}}$ série do Ensino Fundamental, muitas vezes tão subestimados até pelos próprios professores, é realizado esse processamento estratégico. Os alunos já são capazes de usar pertinentemente as expressões nominais referenciais, que colaboram na concretização da sua proposta de sentido.

\section{Referênciais}

ANTUNES, Irandé Costa. Aspectos da coesão do texto: uma análise em editoriais jornalísticos. Recife: Ed. Universitária da UFPE, 1996.

ANTUNES, Irandé Costa. Lutar com palavras: coesão e coerência. São Paulo: Parábola Editorial, 2005.

APOTHÉLOZ, D.; REICHLER-BÉGUELIN, M.-J. Construction de la référence et stratégies de désignation. In: BERRENDONNER, A; REICHLER-BÉGUELIN. Du sintagme nominal aux objets-de-discours. Neuchâtel, Université de Neuchâtel, 1995. p. 143-73.

KOCH, Ingedore G. Villaça. A coesão textual. 17. ed. São Paulo: Contexto, 2002a.

KOCH, Ingedore G. Villaça. Desvendando os segredos do texto. São Paulo: Cortez, 2002b.

KOCH, Ingedore G. Villaça. Introdução à linguística textual: trajetória e grandes temas. São Paulo: Martins Fontes, 2004.

KOCH, Ingedore G. Villaça. MARCUSCHI, L. A. Processos de referenciação na produção discursiva. DELTA, 14: 169-190 (número especial), 1998.

HALLIDAY, M.A.K., HASAN, Rugaia. Cohesion in English. London: Longman, 1976

MONDADA, Lorenza. A referência como trabalho interativo: a construção da visibilidade do detalhe anatômico durante uma operação cirúrgica. In: KOCH, Ingedore V.; MORATO, Edwiges M.; BENTES, Anna Christina (Org.). Referenciação e discurso. São Paulo: Contexto, 2005. p. 11-31.

MONDADA, Lorenza; DUBOIS, D. Construction des objets du discours et categorization: une approche des processus de référenciation. In: BERRENDONNER, A; REICHLER-BÉGUELIN. Du sintagme nominal aux objets-de-discours. Neuchâtel, Université de Neuchâtel, 1995. p. 273-305. 